Results: There were 93 patients, 47 with radiographic sacroilitis (RSPA) and 46 patients without but all - these 46 - had magnetic sacroilitis. This population is Afro-Caribbean for $98 \%$. Mean age at onset of clinical signs is $38.5 \pm 15.0$ years and median age is 37.0 (13-77). An evocative family history is noted in $37 \%$. All these 93 patients suffer from rachialgia.

But the axial complaint is often secondary to the peripheral involvement. 3 patients have a mechanical spinal complaint. All the others have intermittent inflammatory complaint evolving by flares affecting all the spinal stages. 15/93 patients have isolated axial complain without peripheral disease. Enthesopathies are seen in $70 \%$.

Peripheral inflammatory joint complain is observed in 78 patients $(84 \%)$, it is a bilateral and symmetrical chronic polyarticular pattern affecting (70/78) the small joints of the hands, forefeet and wrists. Ankle bi-arthritis is almost systematic and is observed in 71/78 patients; 8 patients with RSPA had no polyarthritis but oligo (6) or monoarthritis (2). Peripheral inflammatory joint is more frequent in NRSPA than in RSPA ( $98 \%$ vs $70 \%)$. Ultrasound individualises grade II synovitis (78/78), rarely with a Doppler effect (5/78). On average, more painful and swollen joints are observed in NRSPA than in RSPA. Extra articular and immunological aspects and activity scores are in table 1.

Good sensitivity of peripheral arthritis to NSAIDs and MTX is noted in 94 and $91 \%$.

Conclusion: NRSpA are not uncommon in the Afro-Caribbean population, but are distinct from Caucasian SpA by several points: female predominance, rarity of B27 and syndesmophytes, frequency of polyalgic pattern, frequency of peripheral arthritis, rarity of extra-articular manifestations, more frequent but less marked inflammation, good response of arthritis to NSAIDs and MTX. Appropriate classification criteria for Afro-descendant populations is an urgent unmet need.

REFERENCES:

[1] (López-Medina C, et al. RMD Open 2019;5:e001108).

Table 1. Extra articular manifestations, activity scores and immunological aspects of the patients.

\begin{tabular}{lcc}
\hline Item & $\begin{array}{c}\text { Results }(\%) \\
\text { NRSPA } n=46\end{array}$ & $\begin{array}{c}\text { Results }(\%) \\
\text { RSPA } n=47\end{array}$ \\
\hline Dactylitis & $11(23 \%)$ & $13(27 \%)$ \\
Uvéitis & $5(11 \%)(\mathrm{p} \mathrm{0.02)}$ & $15(32 \%)$ \\
Psoriasis & $1(2 \%)$ & $1(2 \%)$ \\
IBD & $4(9 \%)(\mathrm{p} 0.02)$ & $10(21 \%)$ \\
Balanitis & 0 & 0 \\
Non gonococcal urethritis & 0 & 0 \\
Non gonococcal cervicitis & 0 & 0 \\
High CRP (at least 2 measure) & $21(45 \%)(\mathrm{p} 0.03)$ & $30(63 \%)$ \\
Mean CRP mg/l & $6 \pm 4$ & $17 \pm 7$ \\
BASDAl & $4.1 \pm 0.2$ & $4 \pm 0.2$ \\
EVA pain & $4.5 \pm 0.4$ & $4,5 \pm 0.2$ \\
HAQ & $0.6 \pm 0.3$ & $0,5 \pm 0.2$ \\
EVA Global & $4.9 \pm 0.8$ & $4,8+0.8$ \\
EVA Spine & $5 \pm 0.5$ & $4,1+0.9$ \\
FIRST score $>5$ & $5 / 46$ patients $(10.9 \%)$ & $6 / 47$ patients $(12.5 \%)$ \\
HLA B27 presence & $4 / 46(8.7 \%)(\mathrm{p} 0.01)$ & $14 / 47(29.8 \%)$ \\
Sexe & male $10(21.3 \%)(\mathrm{p} 0.001)$ & male $19(51.3 \%)$ \\
ACPA & 0 & 0 \\
Latex Waaler-Rose & $1($ low titer, $>65$ years) & 1 (low titer, $>65$ years) \\
ANA & 2 (low titer, $\left.<1 / 320^{\circ}\right)$ & 3 (low titer, $\left.<1 / 320^{\circ}\right)$ \\
\hline
\end{tabular}

Disclosure of Interests: None declared

DOI: 10.1136/annrheumdis-2021-eular.260

\section{POS0946 DISTRIBUTION OF COMORBIDITIES IN SPONDYLOARTHRITIS WITH REGARD TO THE PHENOTYPE AND THE PRESENCE OF PSORIASIS: DATA FROM THE ASAS-COMOSPA STUDY}

M. Á. Puche Larrubia ${ }^{1}$, M. L. Ladehesa Pineda ${ }^{1}$, F. U. Pilar ${ }^{2}$, A. Moltó ${ }^{3}$, C. López-Medina ${ }^{1,3}$, E. Collantes-Estevez ${ }^{1}{ }^{1}$ Reina Sofía University Hospital, Rheumatology, Córdoba, Spain; ${ }^{2}$ University of Cordoba, Rheumatology, Córdoba, Spain; ${ }^{3}$ Cochin Hospital, Rheumatology, Paris, France

Background: Comorbidities have been reported to be more prevalent in patients with Spondyloarthritis (SpA) compared to the general population. Previous studies have suggested that patients with peripheral phenotypes exhibit a higher prevalence of traditional cardiovascular risk (CV) factors compared to those with a predominantly axial phenotype. However, the role of psoriasis in such differences has not been deeply studied.
Objectives: To compare the prevalence of comorbidities (CV, malignancies and osteoporosis (vertebral or peripheral fracture, or low bone mineral density)) between patients with axial and peripheral phenotypes and to evaluate the role of psoriasis in such comorbidities in the whole spectrum of SpA (including psoriatic arthritis).

Methods: Patients from the cross-sectional ASAS-COMOSPA study were classified as having either axial (presence of sacroiliitis on $x$-ray or MRI) or peripheral phenotype (absence of sacroiliitis AND presence of arthritis enthesitis or dactylitis). Patients with each phenotype were divided into two groups depending on the presence or history of psoriasis. Pair-wise comparisons among the four groups (axial and peripheral with psoriasis/withou psoriasis phenotypes) were conducted through univariate logistic regressions and generalized linear mixed models using disease duration and country as fixed and random effects, respectively. Multivariate analysis using were used to evaluate whether psoriasis and the phenotype are independently associated with each comorbidity.

Results: A total of 3291 patients were included in this analysis (mean age 43.6 years, $65 \%$ males). The peripheral phenotype with psoriasis showed the highest prevalence of hypertension (44.9\%), dyslipidaemia (34\%) and diabetes $(8.8 \%)$, while axial phenotype without psoriasis exhibited the lowest prevalence of dyslipidaemia (14.2\%), diabetes (4.1\%) and stroke (0.9\%) (Table 1$)$ Among patients with psoriasis, the axial phenotype showed a significantly [OR, 95\% Cl] lower prevalence of hypertension [OR 0.5, 0.4-0.8] and lower Framingham score [OR $0.97,0.95-0.99$ ] compared to peripheral patients even after adjusting for disease duration and country. Among patients with axial phenotype, patients with psoriasis showed higher prevalence of hypertension [OR 1.8, 1.4-2.2], dyslipidaemia [OR 2.0, 1.7-2.5], diabetes [OR 2.1, 1.4-3.0] and Framingham score [OR 1.0, 1.0-1.1] than non-psoriatic patients. Multivariate analysis confirmed that hypertension, dyslipidaemia and the Framingham score are independently associated with both the psoriasis and the periphera phenotype.

Prostatic cancer and colon cancer were independently associated with the pres ence of psoriasis but not with the phenotype. No differences were found across groups concerning osteoporosis.

Conclusion: Both a peripheral phenotype and the presence of psoriasis were independently associated with an increased CV risk. Psoriasis seems to be associated with a higher prevalence of some malignant diseases, while osteoporosis do not seem to be associated with either phenotype or the presence of cutaneous involvement.

Table 1. Description of comorbidities across the four groups.

\begin{tabular}{lccccc}
\hline & $\begin{array}{c}\text { Psoriatic } \\
\text { axial } \\
\mathbf{N}=\mathbf{4 6 0} \\
\mathrm{n}(\%)\end{array}$ & $\begin{array}{c}\text { Non-psoriatic } \\
\text { axial } \\
\mathbf{N}=\mathbf{2 5 4 1} \\
\mathrm{n}(\%)\end{array}$ & $\begin{array}{c}\text { Psoriatic } \\
\text { peripheral } \\
\mathbf{N}=\mathbf{1 4 7} \\
\mathrm{n}(\%)\end{array}$ & $\begin{array}{c}\text { Non-psoriatic p-value* } \\
\text { peripheral } \\
\mathbf{N}=\mathbf{1 3 6} \\
\mathrm{n}(\%)\end{array}$ & \\
& $27.4(5.5)$ & $25.5(5.5)$ & $27.3(5.7)$ & $26.6(5.3)$ & $<0.001$ \\
\hline BMI, mean (SD) & $135(29.5)$ & $487(19.2)$ & $66(44.9)$ & $25(18.4)$ & $<0.001$ \\
Hypertension & $113(24.8)$ & $359(14.2)$ & $50(34)$ & $23(17)$ & $<0.001$ \\
Dyslipidemia & $37(8.1)$ & $104(4.1)$ & $13(8.8)$ & $7(5.2)$ & $<0.001$ \\
Diabetes & $16(3.5)$ & $51(2)$ & $5(3.4)$ & $2(1.5)$ & 0.162 \\
Ischemic heart disease & $11(2.4)$ & $22(0.9)$ & $3(2)$ & $2(1.5)$ & $\mathbf{0 . 0 2 8}$ \\
Stroke & $9.6(8.7)$ & $6.6(7.5)$ & $11.8(8.8)$ & $5.8(6)$ & $<0.001$ \\
Framingham score, & & & & & \\
$\quad$ mean (SD) & $5(1.8)$ & $5(0.3)$ & $0(0)$ & $0(0)$ & $\mathbf{0 . 0 0 6}$ \\
Prostatic cancer & $(1.7)$ & $3(0.4)$ & $1(1.4)$ & $0(0)$ & 0.181 \\
Breast cancer & $4(0.9)$ & $4(0.2)$ & $1(0.7)$ & $1(0.7)$ & $\mathbf{0 . 0 4 6}$ \\
Colon cancer & $6(1.3)$ & $9(0.4)$ & $1(0.7)$ & $4(3)$ & $<0.001$ \\
Basal cell carcinoma & $0(0)$ & $4(0.2)$ & $3(2)$ & $0(0)$ & $<0.001$ \\
Lymphoma & & & & & \\
\hline
\end{tabular}

*ANOVA or chi-square for continuous and qualitative variables, respectively.

Acknowledgements: This study was conducted under the umbrella of the International Society for Spondyloarthritis Assessment (ASAS).

Disclosure of Interests: None declared

DOI: 10.1136/annrheumdis-2021-eular.306

\section{POS0947 PSORIATIC ARTHRITIS WITH HYPERURICEMIA: MORE PERIPHERAL, DESTRUCTIVE AND CHALLENGINGTO TREAT}

L. Widawski ${ }^{1}$, T. Fabacher ${ }^{2}$, J. E. Gottenberg ${ }^{3}$, L. Spielmann ${ }^{1}$, P. M. Duret ${ }^{1}$, J. Sibilia ${ }^{3}$, L. Messer ${ }^{1}$, R. Felten ${ }^{3} .{ }^{1}$ Hôpitaux Civils de Colmar, Rheumatology, Colmar, France; ${ }^{2}$ Nouvel Hôpital Civil - Hôpitaux Universitaires de Strasbourg, Epidemiology and Public Health, Strasbourg, 